\title{
DISTANCE LEARNING IN TIME OF CRISIS: A CASE STUDY AT THE SCHOOL OF AGRICULTURAL ENGINEERING AND ENVIRONMENT OF UNIVERSITAT POLITĖCNICA DE VALÈNCIA
}

\author{
G. Clemente, A. Garcia-Prats, P. Lisón, C. Rubio, B. Ricarte, V. Estruch-Guitart, \\ L. Fenollosa, J. Manzano, F. Rovira-Más, S. Vidal, M. Vargas, A. San Bautista \\ Escuela Técnica Superior de Ingeniería Agronómica y del Medio Natural. Universitat \\ Politècnica De València (SPAIN)
}

\begin{abstract}
Higher education is continuously evolving to keep up with the challenges posed by the introduction of information and communication technologies (ICT) to education. In this sense, distance learning is booming, with an increasing number of higher education students taking advantage of the flexibility remote learning provides. The School of Agricultural Engineering and Environment (ETSIAMN) of Universitat Politècnica de València (UPV) has been gradually incorporating ICT tools in its bachelor and master degrees for the last two decades. As a result, many college students and university instructors are familiar with ICT techniques. However, the unprecedented COVID-19 crisis has put distance learning in the spotlight like never before, forcing students, faculty, and staff to adapt to the new situation with hardly any preparation time. For that reason, it is convenient to analyse in depth the results and impact of the teaching and evaluation methodologies developed and applied during this critical period, as a way to detect and amend potential inefficiencies in the learning process. The specific goal of this study was to analyse the teaching period during the COVID-19 crisis in ETSIAMN, which covered the spring semester of the academic year 2019-2020. To this purpose, 114 instructors and 274 students were surveyed in July 2020, belonging to four bachelor degrees (agricultural and biological engineering; forestry engineering; food engineering; and biotechnology), and three master degrees (agricultural and biological engineering; forestry engineering, and oenology). Regarding the experimental design for the survey, three main blocks were identified: the first block corresponds to teaching methodologies, comparing students and faculty preferences for distance lecturing; the second block focuses on evaluation modalities and exam configurations; and the final block centers on the difficulties found by both students and lecturers along the adaptation process from conventional to distance teaching. Results showed that instructors and students preferred a combination of live streaming with recorded lectures, being multiple choice the favourite examination type, although many students rated first a project-based evaluation. Overall, students rejected tests with no possibilities to go back on already answered questions, and instructors mostly preferred limiting the time to complete the on-line tests. The lack of motivation was the main barrier encountered by students to achieve an effective learning. Finally, a set of counterweighting measures to improve and promote the successful implementation of distance learning in engineering colleges is proposed.
\end{abstract}

Keywords: higher education, distance learning, COVID-19, on-line teaching, live streaming lecturing.

\section{INTRODUCTION}

In an effort to curb the spread of the COVID-19 pandemic, most governments worldwide temporarily closed educational institutions sometime along the spring of 2020 [1]. Most of the courses initially offered to be followed in person almost overnight had to be transformed into somewhat version of an online class using whatever technology that faculty were familiar with at the time [2]. Maintaining educational continuity with the same level of quality has supposed a huge challenge to them [3]. In this sense, authors are yet emphasizing the difference between those learning activities that were planned and designed to be held online since the beginning, from the temporary shift of instructional delivery to an alternate delivery type due to COVID circumstances, called "Emergency Remote Teaching" [4]. Those activities were planned to be held face-to-face and are expected will return to that format once the pandemic be over [5].

At the Universitat Politècnica de València (UPV) two ICT institution-recommended tools have been available to the faculty for a long time: A tailored educational platform based on Sakai 11.3 named "PoliformaT" and Microsoft Office 365 that includes the communication and collaboration platform Microsoft Teams. However, those tools allow a wide variety of techniques for both teaching (i) and 
evaluation (ii), such as i) online streaming synchronous classes, recorded lectures, online office hours, project and case studies, etc. and ii) open response exam, multiple choice exam, chores, etc.

Online teaching and learning in pandemic circumstances is not exempt from barriers and difficulties related to a) students' ICT technology accessibility, b) internet teaching staff self-efficacy, and c) student engagement and motivation [6]. Many students lacked an adequate Internet connection at home or had to share it with other family members in the same situation. In other cases, only one personal computer or ICT device was available at home for the whole family. Regarding the barriers that faculty had to face we could identify the necessity of learning new software, transform teaching resources to be used on-line, balancing their new family life and work in the same space and the disconnection feeling from the students. To finish with, In regards to the barriers related to the student's motivation, we could mention the difficulty of maintaining the engagement in the absence of interaction, perceived isolation and family commitments [7].

This work aims at analysing the teaching period during the COVID-19 crisis in ETSIAMN, which covered the spring semester of the academic year 2019-2020 in which the campus remained closed down and students came back home. We assessed the results and impact of both teaching and evaluation methodologies developed and applied during this critical period from both student and faculty sight, as a way to detect and amend potential inefficiencies in the learning process.

\section{METHODOLOGY}

A total of 114 instructors and 274 students were surveyed in July 2020, belonging to four bachelor degrees (agricultural and biological engineering; forestry engineering; food engineering; and biotechnology), and three master degrees (agricultural and biological engineering; forestry engineering, and oenology).

To carry out the surveys, the management tool for teaching available at the Universitat Politècnica de València called PoliformaT has been used. It is an online platform where both teachers and students have at their disposal everything they need to teach or follow their subjects: space for subjects and their materials, online courses, spaces for homework or exams. In particular, the PoliformaT exam tool is endowed with great functionality and is highly configurable, allowing the creation of a test with survey-type questions and anonymous correction where, in addition, the answers can be accessed at any time. After the survey is finished, you provide your statistics, first a general one with the number of participants, followed by more detailed information per question.

\section{RESULTS}

The specific goal of this study was to analyse the teaching period during the COVID-19 crisis in School of Agricultural Engineering and Environment (ETSIAMN), covering the spring semester of the academic year 2019-2020. To this purpose, students and lecturers' preferences were surveyed for different aspects of distance lecturing, including teaching methodologies, evaluation modalities and exam configurations; and the difficulties found by both students and lecturers along the adaptation process from conventional to distance teaching.

\subsection{Analysis of Students preferences for distance learning}

The first part of the survey performed to students included some questions to better characterize the population, including: (i) student population by degree (Table 1), (ii) student registration by curricular year with more credit hours (Table 2), student mobility (Table 3 ), number of courses completed during the pandemic period for spring semester 2020 (Table 4), and courses registering for second (or more) times (Table 5). A total of $91 \%$ of the surveyed students were undergraduates, being the bachelor degree on agricultural and biological engineering the most represented degree, with a total of 98 surveyed students. Regarding the curricular year, the students were distributed along all of them, observing a slight decrease in the $4^{\text {th }}$ year. A percentage of $16 \%$ of the students belonged to a mobility program. Finally, $82 \%$ of the surveyed students were completing at least 5 courses during the pandemic period for Spring Semester (2020), being $81 \%$ of the students enrolled in that courses for the first time. All these data indicate that a representative population of students belonging to the ETSIAMN have been surveyed. 
Table 1. Student population by degree or master degree

\begin{tabular}{|l|c|}
\hline \multicolumn{1}{|c|}{ Degree or Master Degree } & Number Students \\
\hline B. Eng. in agricultural and biological engineering & 56 \\
\hline B. Eng. in forestry engineering & 17 \\
\hline B. Eng in food engineering & 98 \\
\hline B. Sc. in biotechnology & 77 \\
\hline Master in agricultural and biological engineering & 19 \\
\hline Master in forestry engineering & 2 \\
\hline Master in oenology & 5 \\
\hline Total & 274 \\
\hline
\end{tabular}

Table 2. Student registration by curricular year with more credit hours

\begin{tabular}{|l|c|}
\hline \multicolumn{1}{|c|}{ Curricular year with more credit hours } & Number of students \\
\hline 1st year & 85 \\
\hline 2nd year & 76 \\
\hline 3rd year & 67 \\
\hline 4th year & 45 \\
\hline
\end{tabular}

Table 3. Student mobility.

\begin{tabular}{|c|c|}
\hline Mobility & Number of students \\
\hline Yes & 42 \\
\hline No & 224 \\
\hline
\end{tabular}

Table 4. Number of courses completed during the pandemic period for Spring Semester (2020).

\begin{tabular}{|c|c|}
\hline Number of courses & Number of students \\
\hline 1 & 4 \\
\hline 2 & 4 \\
\hline 3 & 11 \\
\hline 4 & 28 \\
\hline 5 & 102 \\
\hline 6 & 117 \\
\hline
\end{tabular}

Table 5. Courses registering for second (or more) times

\begin{tabular}{|c|c|}
\hline $\begin{array}{c}\text { Courses registering for second } \\
\text { (or more) times }\end{array}$ & Number of courses \\
\hline 0 & 216 \\
\hline 1 & 26 \\
\hline 2 & 12 \\
\hline 3 & 8 \\
\hline 4 & 3 \\
\hline 5 & 2 \\
\hline 6 & 0 \\
\hline
\end{tabular}

The second part of the survey included questions on preferences regarding several aspects of the distance learning, including teaching methodologies, evaluation modalities and exam configurations; and the difficulties found. As Figure 1 shows, student preference for the teaching methodologies were very well distributed into the three presented options, being the combination of recorded material 
together with live streaming in the regular course schedule the favourite preference, including 91 students choosing this methodology.

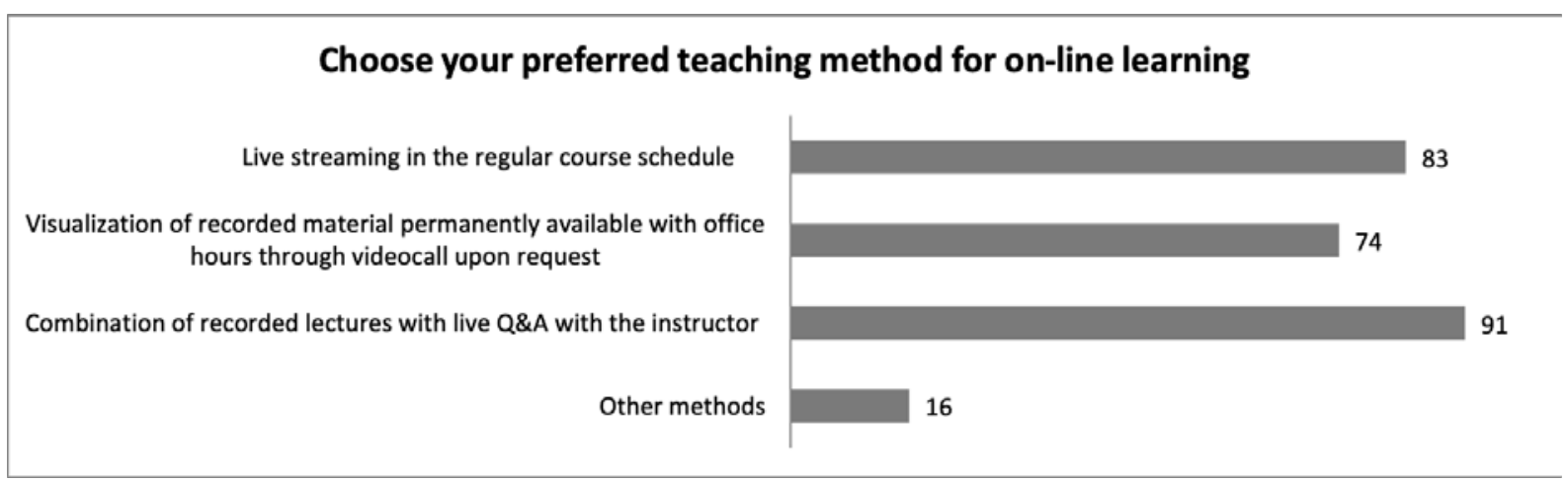

Figure 1. Student preference for teaching methodologies in distance learning.

Regarding the evaluation, two different dimensions were explored: method and exam configuration. Students selected case-based projects and multiple choice exams as the most objective methods, being the oral exam the least-liked preference (Figure 2). Interestingly, an outstanding preference for test with possibility to go back to previous pages or sections is shown in Figure 3.

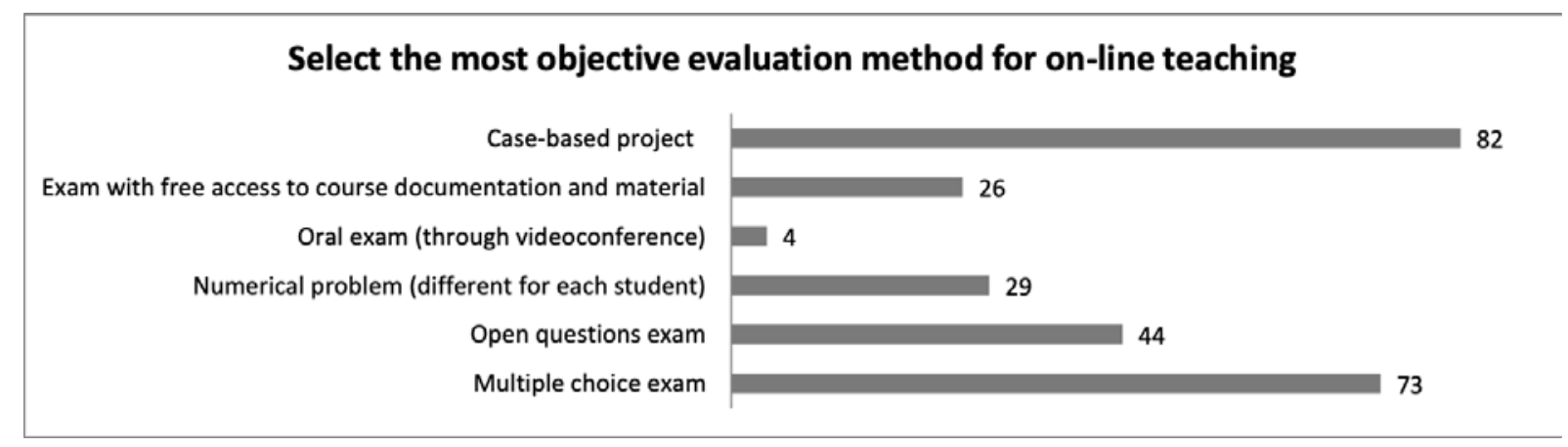

Figure 2. Student preference for evaluation modalities in distance learning.

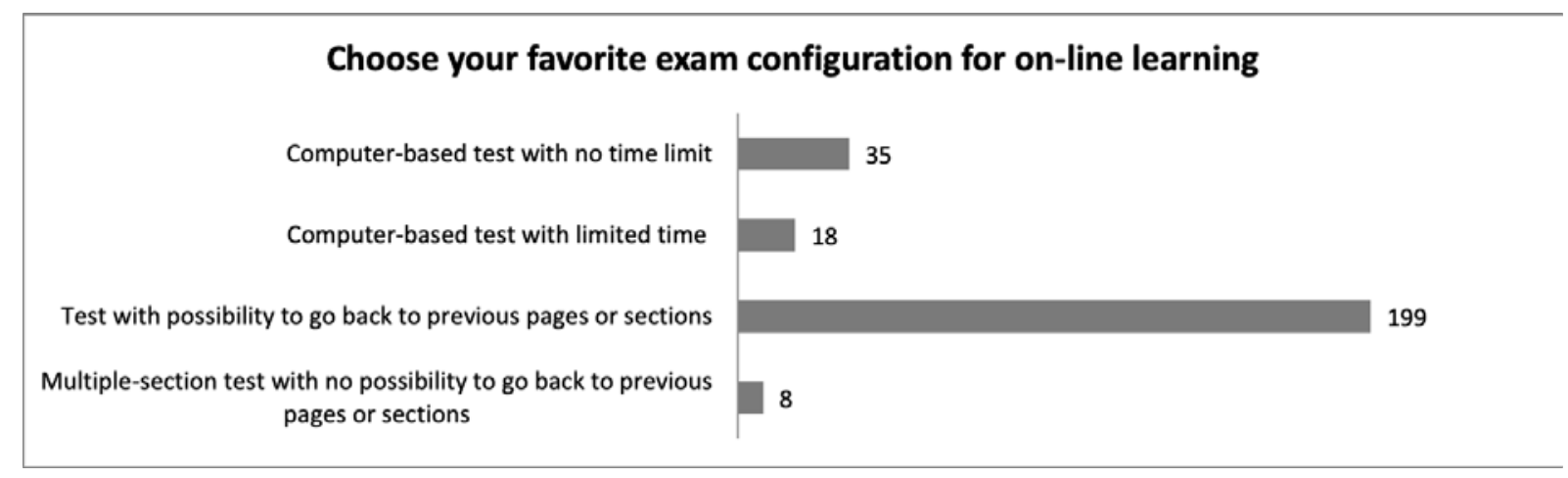

Figure 3. Student preference for exam configurations in distance learning.

Finally, students were asked for their main difficulties in distance learning during the pandemic period for spring semester 2020, having the possibility of selecting several options. As Figure 4 shows, 47 students declared no finding difficulties, representing around $20 \%$ of the surveyed. Besides, more than 100 students indicated a clear lack of motivation was detected or technical difficulties in stablishing connection. 


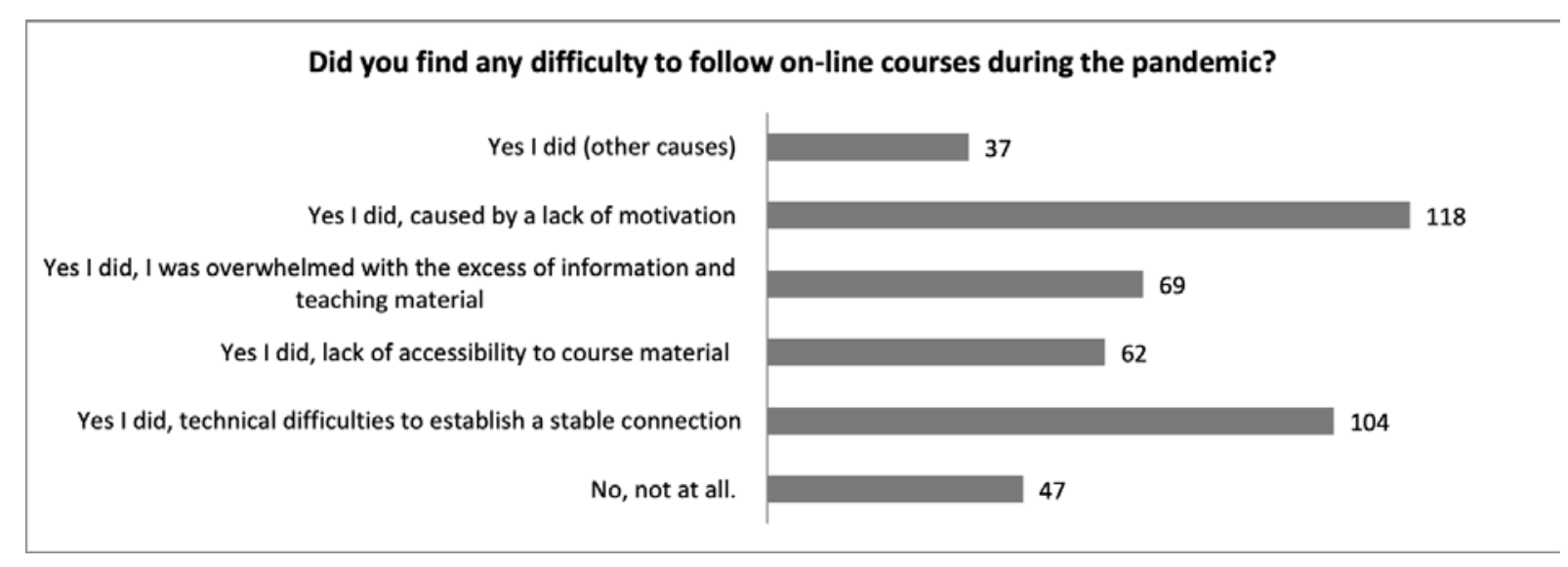

Figure 4. Students' difficulties in distance learning.

\subsection{Analysis of Lecturers preferences for distance learning}

In a similar manner to the student survey, the first part of the survey performed to lecturers included some previous questions, including: (i) lecturer population by degree (Table 6), and (ii) lecturer experience during COVID-19 crisis period (Table 7). Around $50 \%$ of the surveyed lecturers normally teach in the bachelor degree on agricultural and biological engineering or on biotechnology, with a total of 45 and 46 surveyed lecturers, respectively. Besides, $23 \%$ of the lecturers had experience in teaching in master degrees. Finally, $83 \%$ of the lecturers had experience on teaching during COVID19 crisis in spring semester 2020. Our data indicates that a representative population of lecturers from the ETSIAMN with experience in distance learning during COVID-19 crisis was surveyed.

Table 6. Lecturer population by degree

\begin{tabular}{|l|c|}
\hline \multicolumn{1}{|c|}{ Degree or Master Degree } & Number of lecturers \\
\hline B. Eng. in agricultural and biological engineering & 45 \\
\hline B. Eng. in forestry engineering & 20 \\
\hline B. Eng in food engineering & 34 \\
\hline B. Sc. in biotechnology & 46 \\
\hline Master in agricultural and biological engineering & 26 \\
\hline Master in forestry engineering & 7 \\
\hline Master in oenology & 11 \\
\hline Total & 189 \\
\hline
\end{tabular}

Table 7. Lecturer experience during COVID-19 crisis period.

\begin{tabular}{|c|c|}
\hline $\begin{array}{c}\text { Distance learning experience } \\
\text { during COVID-19 crisis }\end{array}$ & Number of lecturers \\
\hline Yes & 92 \\
\hline No & 19 \\
\hline
\end{tabular}

Results corresponding to the second part of the lecturers' surveys included questions on preferences regarding several aspects of the distance learning, similar to those asked to the students (Figures 5, 6 and 7). Lecturers' preferred choice for teaching methodology was the combination of recorded material together with synchronous teaching in the regular course schedule, choosing this combined methodology 53 lecturers out of a total of 140 (Figure 5). 
What on-line teaching methodology would you choose to grant a successful learning process for students?

Live streaming in the regular course schedule Visualization of recorded material permanently available with office hours Combination of recorded lectures with live Q\&A with the instructor Other methods

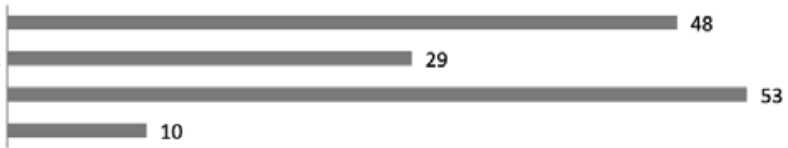

Figure 5. Lecturer preference for teaching methodologies in distance learning.

As Figure 6 shows, multiple choice exams was clearly the most preferred evaluation method in distance learning for lecturers, representing around $30 \%$ of the options voted on. Regarding the exam configuration, an outstanding preference for limited time was expressed by lecturers and no special preferences for test with possibility to go back or not was shown by them (Figure 7).

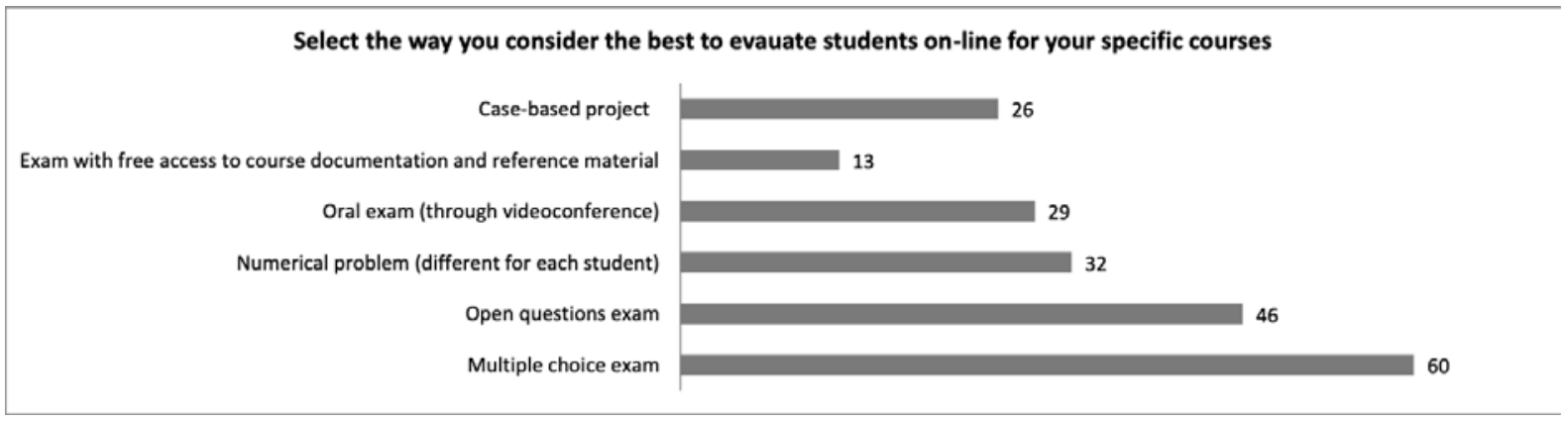

Figure 6. Lecturer preference for evaluation modalities in distance learning.

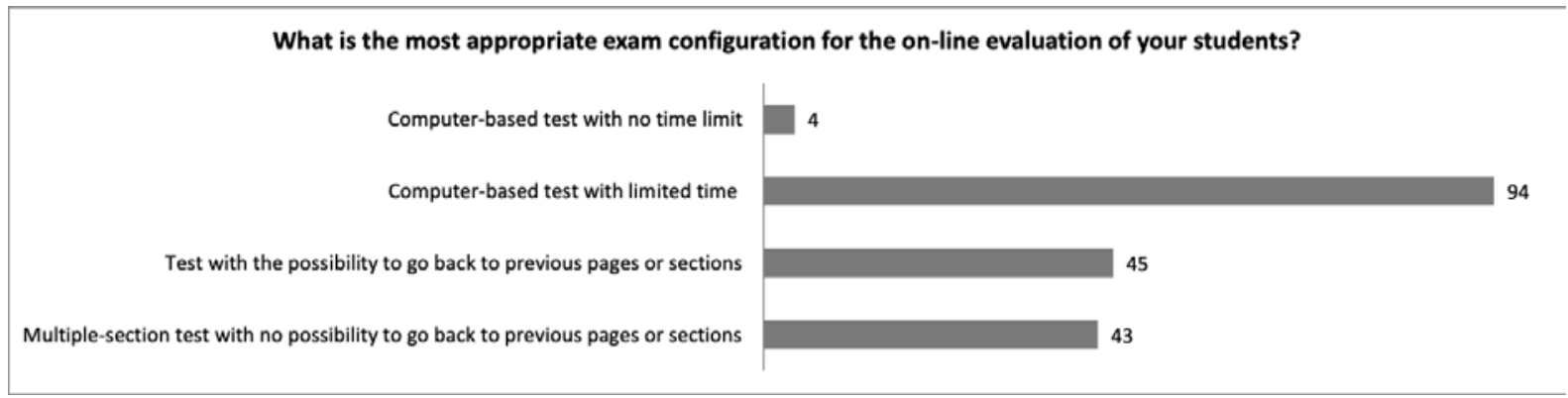

Figure 7. Lecturer preference for exam configurations in distance learning.

\subsection{Comparison between Students and Lecturers preferences for distance learning}

Finally, a comparison between students and lecturers' preferences for distance learning was performed in terms of percentages. A chi-square test of homogeneity with a $p$-value of 0.456 confirms that there are no significant differences in the question in Figure 8 [8-9]. It can be appreciated that both collectives have very similar preferences on teaching methodology, being the combination of recorded material and live streaming the most desirable option.

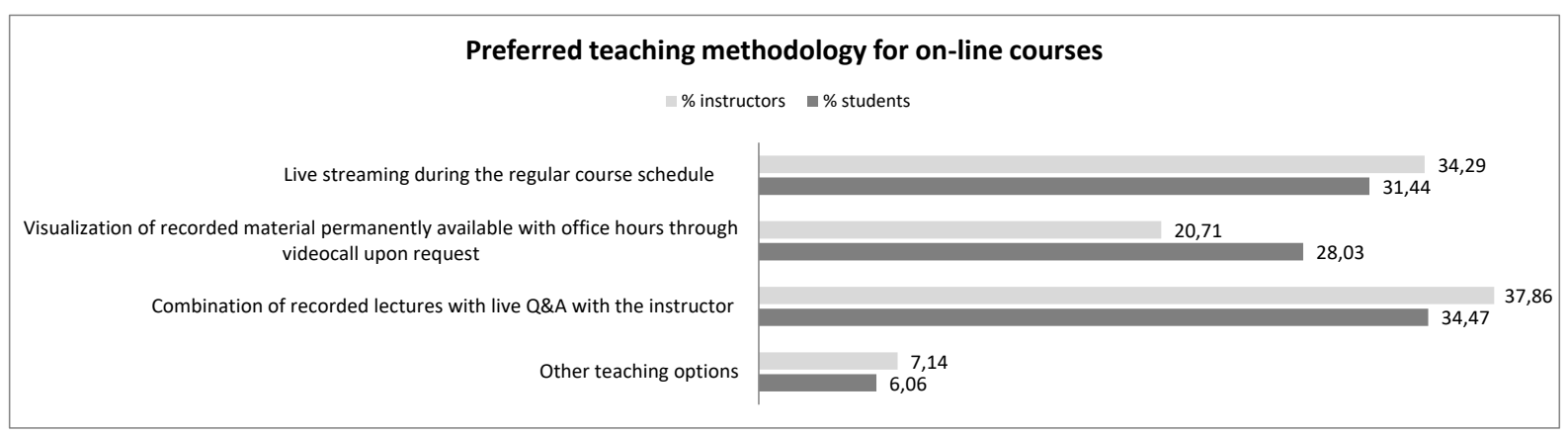

Figure 8. Comparison between Students and Lecturers preferences for teaching methodology in distance learning 
On the contrary, clear differences on evaluation modalities and configurations of exams were observed between students and lecturers' preferences. In both cases the homogeneity test was statistically significant with a $p$-value of 0.000 . The low percentage of students choosing oral exam as the preferred evaluation technique $(1.55 \%$ of the surveyed students) contrasts with the $14 \%$ of the lecturers selecting this choice. An outstanding difference was also observed in the case-based project modality, which resulted to be the most suitable evaluation modality for students, with only a $12,62 \%$ of lecturers interested in this technique of evaluation (Figure 9).

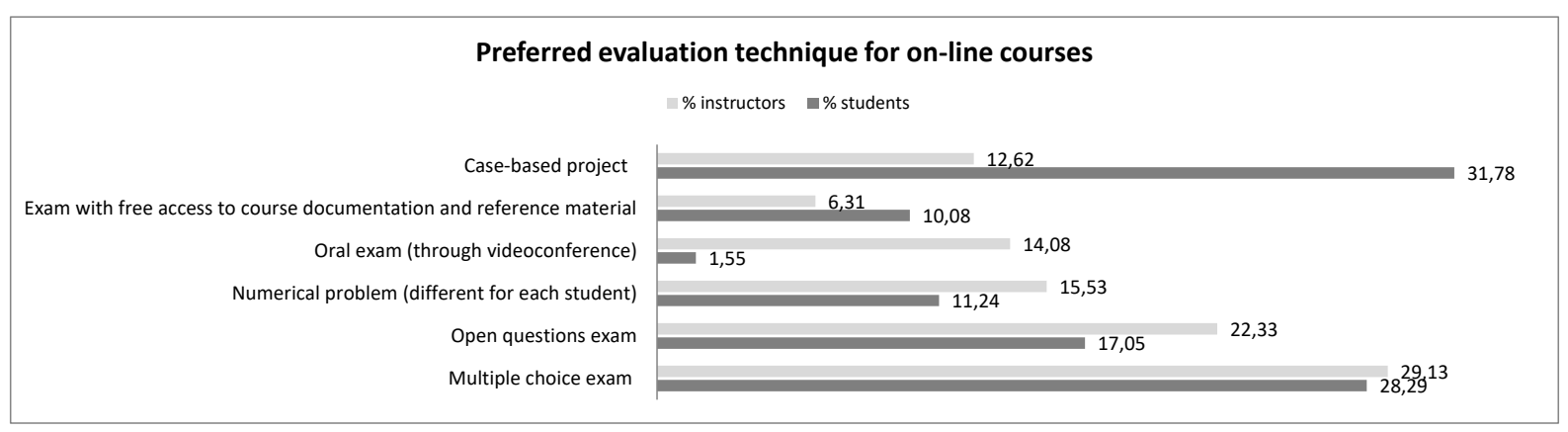

Figure 9. Comparison between Students and Lecturers preferences for evaluation modalities in distance learning

As Figure 10 shows, while lecturers were very much worried in the limited time of the tests, students expressed a clear preference for tests with possibility to go back to previous pages or sections.

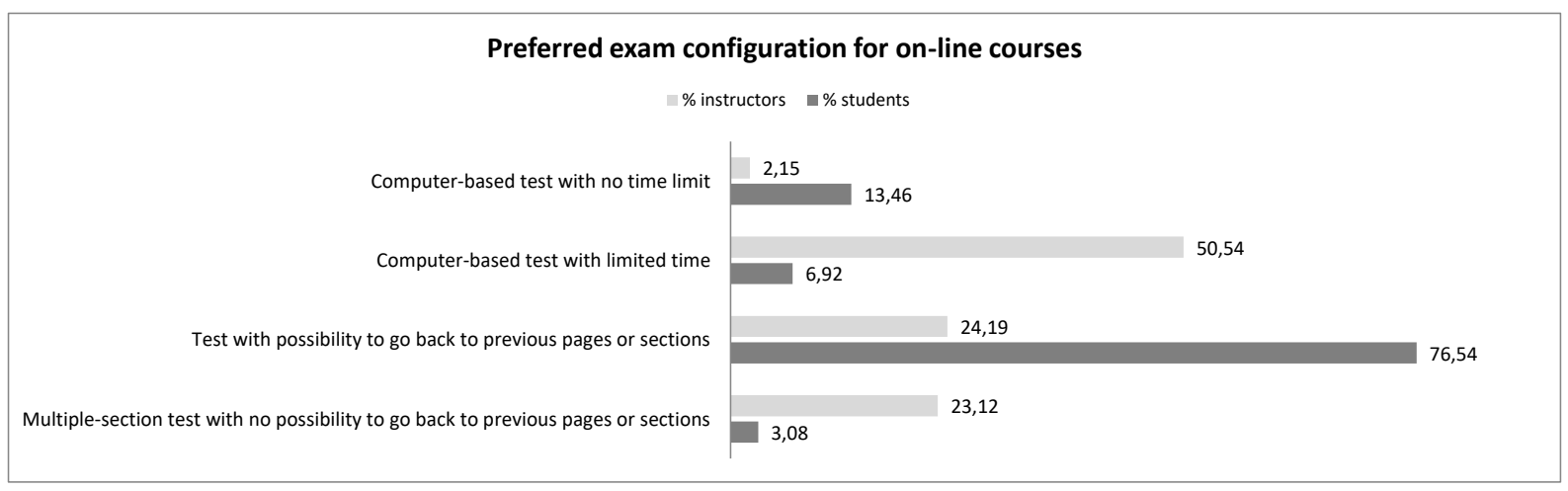

Figure 10. Comparison between Students and Lecturers preferences for exam configurations in distance learning

\section{CONCLUSIONS}

Lecturers and students agree in preferences for teaching methodologies in distance learning, whilst clear differences in the preferences for evaluation modalities and formats have been detected.

In regards to the barriers that students had to face in this unprecedented experience, two of them stood out among the others: the internet connection quality and the lack of motivation. The first one would be explained due to the fact that there was no expectation of being confined. Students have very good internet service at the University and only a minimum connection at home is needed. However, there is a real concern about the second one. The Emergency Remote Teaching was not attractive enough to motivate and engage the students to the learning process and this aspect should be revised in the near future.

\section{REFERENCES}

[1] UNESCO (2020). COVID19 Educational Disruption and Response. Retrieved from: https://en.unesco.org/covid19/educationresponse/

[2] Christina Romero-Ivanova, Michael Shaughnessy, Laura Otto, Emily Taylor \& Emma Watson Digital Practices \& Applications in a Covid-19 Culture. Higher Education Studies; Vol. 10, No. 3; 2020 
[3] Dietrich, N., Kentheswaran, K., Ahmadi, A., Teychené, J., Bessière, Y., Alfenore, S., Laborie, S., Bastoul, D., Loubière, K., Guigui, C., Sperandio, M., Barna, L., Paul, E., Cabassud, C., Liné, A., Hébrard, G., 2020. Attempts, Successes, and Failures of Distance Learning in the Time of COVID-19. J. Chem. Educ. 97, 2448-2457. doi:10.1021/acs.jchemed.0c00717

[4] Hodges, C., Moore, S., Lockee, B., Trust, T., \& Bond, A. (2020). The difference between emergency remote teaching and online learning. Educause Review, 27 March. Retrieved from: https://er.educause.edu/articles/2020/3/the-difference-between-emergency-remote-teaching-andonline-learning. Accessed 15 June 2020.

[5] Rapanta, C., Botturi, L., Goodyear, P., Guàrdia, L., Koole, M., 2020. Online University Teaching During and After the Covid-19 Crisis: Refocusing Teacher Presence and Learning Activity. Postdigital Sci. Educ. doi:10.1007/s42438-020-00155-y

[6] Dhawan, S., 2020. Online Learning: A Panacea in the Time of COVID-19 Crisis. J. Educ. Technol. Syst. 49, 5-22. doi:10.1177/0047239520934018

[7] Roddy, C., Amiet, D.L., Chung, J., Holt, C., Shaw, L., McKenzie, S., Garivaldis, F., Lodge, J.M., Mundy, M.E., 2017. Applying Best Practice Online Learning, Teaching, and Support to Intensive Online Environments: An Integrative Review. Front. Educ.

[8] Fisher, R.A. On the interpretation of $X 2$ from contingency tables, and the calculation of P. J. R. Stat. Soc. 1922, 85, 87-94.

[9] Pearson, K. On the criterion that a given system of deviations from the probable in the case of a correlated system of variables is such that it can be reasonably supposed to have arisen from random sampling. Philos. Mag. 1900, 50, 157-175. 